\title{
Analysis of the Agricultural Product Live Broadcasting Selling Industry in the Era of Big Data
}

\author{
Xingda $\mathrm{Zhu}^{1}$ \\ ${ }^{1}$ No.31, Xincheng Nanguan, Tongzhou District, Beijing, China
}

\begin{abstract}
During the coronavirus outbreak, many agricultural products are unsalable in China. In the era of big data, the live broadcasting selling of agricultural products has attracted more and more attention as a new medium of marketing. Farmers, Internet celebrities, and even government officials sell agricultural products on the live broadcasting, allowing various types of agricultural products to be sold throughout the country, which promoted the development of the agricultural live broadcasting selling industry and sped up economic recovery. This article discusses the current situation of live broadcasting of agricultural products, including their advantages, problems, and prospects, combined with actual live broadcasting cases and data, in order to provide references for other industries.
\end{abstract}

\section{INTRODUCTION}

Diversified industries in China have been damaged to varying degrees affected by the epidemic coronavirus, among which agriculture and animal husbandry are suffering more. The main reasons include reduced purchases, which is caused by the decline in public income and stagnant transportation due to regional blockades. Under such an emergent moment, live broadcasting, one of the new online sales approaches, provides Chinese farmers with proper promotion and sales channels. The government, farmers, and online celebrities work together to use the live broadcasting to create good sales of agricultural products continuously. Live broadcasting helps farmers and promotes China's economic recovery, which creates magic during coronavirus spread. This paper aims to provide the necessary knowledge and suggestions for people in the live broadcasting industry by analyzing the advantages, disadvantages, and prospects. The author hopes that more people could eager to learn about live broadcasting and utilize it to promote agricultural sales.

\section{CURRENT SituATION OF THE LIVE BROADCASTING INDUSTRY}

According to the 45th "Statistical Report on China's Internet Development Status" released by CNNIC, the report shows that as of March 2020, the number of live broadcasting users in China has reached 560 million, accounting for $62.0 \%$ of the total netizens. Among them, the number of e-commerce live broadcasting users that emerged and achieved rapid development in 2019 is 265 million, accounting for $29.3 \%$ of the total netizens [1].

The massive number of users in the live broadcasting has created a new agricultural retail model with the xingdazhu2002@163.com combination of traditional industries and Internet technology, which has become a hot spot recently. A series of platforms such as Taobao and TikTok provides agricultural producers with a way to promote and sell crops in live broadcasting, which has made significant innovations in the traditional e-commerce industry. During the epidemic, live broadcasting of agricultural products opened up sales channels for unsold agrarian products, provided the determination for farmers who are in trouble, and provided approaches for the public to assist farmers.

\section{AdVANTAges OF THE AGRICULTURAL PRODUCT LIVE BROADCASTING SELLING INDUSTRY}

\subsection{The authenticity of products}

Live broadcasting is a new type of sales method with live broadcasters as the carrier. Because live broadcasters can try and introduce the products in person, they will be more credible for consumers. Electronic Word of Mouth (eWOM) can help people better understand the strategies which make live broadcaster trustful. eWOM refers to any positive or negative statement that is made by potential, actual, and former customers about a product or company via the Internet. Word of mouth is known to be one of the most credible and trusted sources of marketing. Social media influencers are masters at eWOM and they take on the role of forming consumers' opinions on products and services [2]. As a result, when live broadcasters provide positive feedback for products, consumers are more likely to purchase them.

Simultaneously, compared with the traditional marketing method of e-commerce using pictures and text, 
the live video can ensure that the crop's image has not undergone post-processing and can approve its quality. Live broadcasting also has the interactive characteristics of traditional media. Through instant barrage subtitles, businesses and consumers can establish contact. Merchants can answer the audience's questions in a targeted manner based on the barrage subtitle, helping them understand the product faster and better. On April 12, 2020, the county magistrate of Shixing County, Shaoguan City, Ye Hongfan, sold local loquat through live broadcasting. Through the publicity at the loquat garden, the audience can observe the natural planting environment. In the live broadcasting, he also introduced the characteristics and effects of loquat. Finally, he tasted the loquat to let the audience have a more intuitive experience of the loquat's quality. In just one hour, loquat sales exceeded 236,000 boxes, with sales reaching RMB 2.124 million. Wu Kangxiu, the county magistrate of Xuwen County, Zhanjiang City, sold pineapples in the live broadcasting. Live broadcasting was only half an hour, attracting 300,000 people to watch and place orders. 150,000 boxes of pineapples were sold out within two hours [3].

\subsection{Better advertising of products}

The advertising of live broadcasters can differentiate agricultural products. In traditional fresh food marketing, supermarkets and distributors do not play a useful role in product advertising. For example, the labeling content of fresh food in China only includes product name, place of origin, production date, producer supplier name, address, contact information, etc [4]. Consumers cannot know anything other than the basic information. In contrast, live broadcasting can make up for this defect.

Some specific crops have unique effects on human health. For example, lychee can nourish the brain and spleen, strengthen the body, and promote appetite. In ancient times, it was a precious ingredient and a tribute to the royal family. Emperor Li Longji of the Tang Dynasty ordered people to transport lychees from the south to the palace, and several horses died because of long transportation. In addition, the same agricultural products have different characteristics in different regions. A typical example is a green tea, as its taste and quality are different in various regions. The tea produced in the mountains around Longjing Village, West Lake, Zhejiang, has exceptionally high quality. The premium West Lake Longjing tea has a fresh and high aroma with a refreshing taste. It is known as West Lake Longjing tea, one of the top ten teas in China.

In live broadcasting marketing, live broadcasters have more time to introduce features weakened by traditional marketing. By telling stories and telling the advantages, consumers are more likely to understand the differences, advantages, and disadvantages of different agricultural products. High-quality agricultural products are known to customers and can be sold at higher prices, helping farmers achieve higher profits.

\subsection{Lower price and higher profits}

Unlike the traditional selling model associating with farmers, distributors and consumers, online live broadcasting significantly reduces intermediate links. A series of costs, including distributors, online shop commissions, and transportation, have been reduced. Consumers can buy high-quality products at a lower price, while farmers can also enjoy higher profits.

\subsection{Help and support farmers}

Through investigations, the government can find farmers with difficulties to provide targeted assistance. The survey team can classify farmers through different indicators and adjust their priorities to help more people. For perishable crops such as bananas and peaches, the government should help people sell products through live broadcasting as soon as possible. The priority of easy-storable crops, such as walnuts and potatoes, can be lowered. Besides, some popular products such as Yangcheng Lake hairy crabs require little or no help because the market demand can fully meet its production capacity. However, like some unpopular crops, there are often unsalable situations. The government must help it build the brand. These different treatments can help people to allocate resources on farmers that need more help. The government should not ice on the cake but provide timely assistance.

\subsection{Marketing by celebrities}

Celebrities can significantly influence consumers' behavior and cause consumers' purchasing when celebrities advertise in live broadcasting. The following theory can explain this behavior. "Based on informative feedback, they (consumers) develop thoughts or hypotheses about the types of behavior most likely to succeed. These hypotheses then serve as guides for future actions" [5].

Moreover, celebrities usually have many fans, allowing more people to know about products and cause purchasing. For example, the combination of CCTV host Zhu Guangquan and Li Jiaqi has sold 40.14 million yuan worth of Hubei goods through two-hour live broadcasting. On April 10, 2020, Luo Yonghao, who has 11.29 million TikTok fans, sold Hubei Zigui Spring Orange and sold 120,000 pieces of its inventory in 11 seconds [6].

\section{SHORTCOMINGS OF THE AGRICULTURAL PRODUCT LIVE BROADCASTING SELLING INDUSTRY}

\subsection{Misleading advertising}

In the process of the live broadcasting selling of agricultural products, broadcasters often exaggerated products' quality. Some broadcasters do not have sufficient identification for the products and ignore the quality deficiencies of the products. What is more, some people exaggerate the product's effectiveness because 
they are not responsible for the quality of the product; thus, it is difficult for consumers to get a proper solution after purchasing defective products [7]. Local governments should take the lead in monitoring live broadcasting to prevent such things from happening. As a new retailing model, live broadcasting has not established a strong trust relationship between producers and consumers. If broadcasters made fraud for temporary benefits, it would significantly harm the entire region's credibility and even the live broadcasting selling industry.

\subsection{Impairing farmers' benefits}

Many live broadcasters disregard the benefits of farmers to earn personal gains and attract attention. Fighting price wars and purchasing fake traffic happen from time to time. For the sound development of live broadcasting selling of agricultural products, live broadcasters must keep in mind the basic principles of serving farmers, and do not pass on the cost of publicity and price wars to farmers. The government must resolutely eliminate the behavior that only focuses on "flow" and ignores "quality." Letting farmers and consumers enjoy welfare is the most important thing.

\section{DeVelopment TREnd OF Agricultural PRODUCTS LIVE BROADCASTING SELLING INDUSTRY}

\subsection{Help local agricultural products to establish the brand effect}

Live broadcasting's ultimate goal is to help agricultural products flourish after leaving the live broadcasting and building their brand. Only when agricultural products are well known to the public due to their publicity and excellent quality, can they break away from support and develop independently, and win welfare for farmers and drive regional development. The most famous Yangcheng Lake hairy crabs in China, and China Chucheng, a sweet and delicious orange, have established an excellent brand effect through publicity and has become the first choice for gifts.

TABLE 1. MARKET SIZE OF BRANDED AGRICULTURAL PRODUCTS [8]

\begin{tabular}{|c|c|c|}
\hline & $\begin{array}{c}\text { Market size and expectation } \\
\text { of Yangcheng Lake hairy } \\
\text { crabs (billion RMB) }\end{array}$ & $\begin{array}{c}\text { Sale of China Chucheng } \\
\text { (million tons) }\end{array}$ \\
\hline 2016 & 64.8 & \\
\hline 2017 & 77.8 & $100+$ \\
\hline 2018 & 98.2 & $200+$ \\
\hline 2019 & 105.7 & \\
\hline 2020 & 122.0 & 200 \\
\hline
\end{tabular}

There are excellent crops in all regions of China. Farmers, regions, and governments should consciously support and use professional knowledge and talents to build brands for various agricultural products. In this way, even if the crops are not supported by live broadcasting, they can still have high sales.

\subsection{Full development of the supply chain}

The live broadcasting of agricultural products is associated with broadcasters' ability and the cooperation of all links. The entire process, from production to processing, promotion, sales, and distribution, constitutes a complete supply chain. Neither e-commerce company nor farmers alone can complete the entire process. If the live broadcasting industry wants to continue to develop, every link should be of high quality and make fewer mistakes to give users a better shopping experience. 


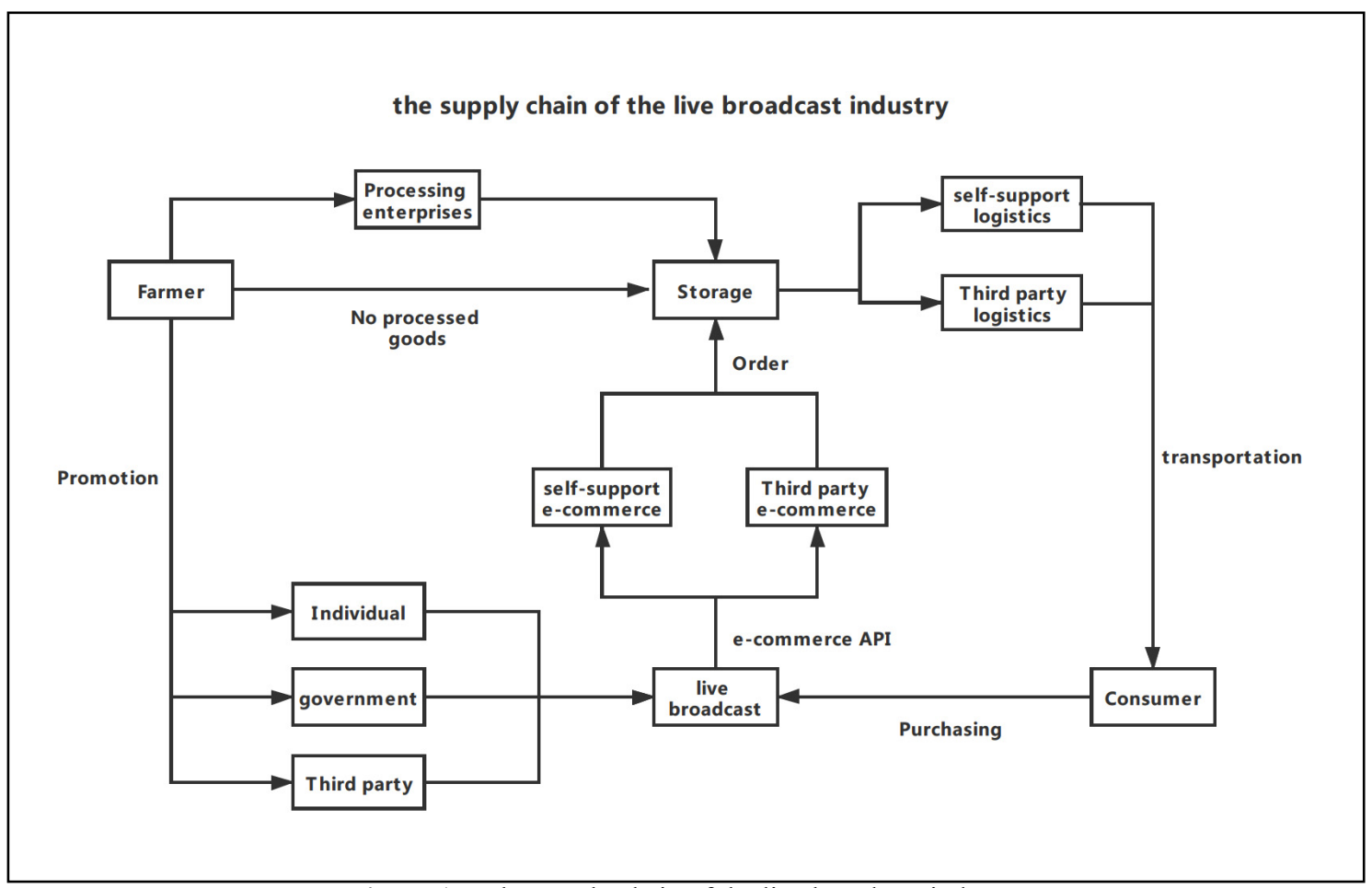

Figure 1. The supply chain of the live broadcast industry

Figure 1 above describes the live broadcasting selling industry's whole supply chain, including the production stage, transportation stage, advertising stage, and the live broadcasting platform's internal logic when placing orders.

In the promotion stage, the government should take the lead and train high-level live broadcasters. The government should play a role in training, education, and other functions. It is necessary to give farmers technical support and hardware matching through training and teach farmers how to do live broadcasting. Through theoretical study, live broadcasters can use live broadcasting tools to attract audiences and facilitate transactions. If farmers choose to promote through a third party, such as an Internet celebrity, farmers and the platforms must conduct a strict review. Ensure the professionalism of the broadcasters to achieve the best results.

In the distribution stage, there must be a mature and systematic network. Various types of agricultural products must have corresponding delivery methods. There must be regular and special distribution approaches such as cold chain and aviation to ensure the timeliness of distributing perishable items. The company must take responsibility and bear the consequences. Farmers should not be responsible for improper delivery, which hurts the brand name.

\section{CONCLUSION}

As a new sales and marketing method in the big data era, live broadcasting has its unique advantages. Sales data and cases also prove that this method can be widely and effectively used in reality. The society could believe that live broadcasting can help farmers generate income during the epidemic and serve as a supplement to traditional distributor channels and e-commerce channels after the epidemic. Based on major live broadcasting customers, various regions should develop unique agricultural brands to thrive without relying on live broadcasting. The government should actively support and strictly supervise the live broadcasting selling industry and avoid damaging the industry's overall reputation due to individual problems. At the same time, it is necessary to develop complete supply chains and create more jobs in order to create a prosperous market.

\section{ACKNOWLEDGMENT}

First and foremost, I would like to show my deepest gratitude to professor Zhang, who has provided me with valuable guidance in every stage of this article writing. Further, I would like to thank all my friends and family members for their encouragement and support. Without all their enlightening instruction and extraordinary kindness, I could not have completed my thesis.

\section{REFERENCES}

1. Shan J. Y., "Research on the influence and value extension of agricultural products live Streaming Industry in the era of big data", 2020.

2. Morgan Glucksman, "The Rise of Social Media Influencer Marketing on Lifestyle Branding: A Case Study of Lucie Fink," Elon Journal of undergraduate research in communications. p.79, fall 2017.

3. Lu Z. K., "Under the epidemic, officials live broadcasting with goods to lead the new trend", 2020 [Online] Available: 
http://news.southcn.com/nfzz/content/2020-04/30/co ntent_190830238.htm [Accessed on 2020/9/3]

4. "Supermarket fresh food packaging and labeling management standards," 2015 [Online] Available: https://wenku.baidu.com/view/7447389a4b35eefdc9 d33350.html [Accessed on 2020/9/3]

5. Morgan Glucksman, "The Rise of Social Media Influencer Marketing on Lifestyle Branding: A Case Study of Lucie Fink," Elon Journal of undergraduate research in communications. Vol. 8, p79, 2017.

6. Zhang Z. X., "how can Agricultural products live broadcasting move steadily", 2020 [Online] Available:

http://www.zgcxjrb.com/zgcxjrb/zjgd/webinfo/2020/ 08/1596905662398262.htm [Accessed on 2020/9/4]

7. Shan J. Y., "Research on the influence and value extension of agricultural products live Streaming Industry in the era of big data." , 2020.

8. Xinshicai, "New Yangcheng Lake hairy crab trend: market size of over 100 billion yuan in 2019", 2019. 